\title{
Artificial Engine Sound Synthesis Method for Modification of the Acoustic Characteristics of Electric Vehicles
}

\author{
Dongki Min, Buhm Park, and Junhong Park \\ Department of Mechanical Engineering, Hanyang University, Seoul 133-791, Republic of Korea \\ Correspondence should be addressed to Junhong Park; parkj@hanyang.ac.kr
}

Received 15 January 2018; Accepted 6 March 2018; Published 10 April 2018

Academic Editor: Marcello Vanali

Copyright (C) 2018 Dongki Min et al. This is an open access article distributed under the Creative Commons Attribution License, which permits unrestricted use, distribution, and reproduction in any medium, provided the original work is properly cited.

\begin{abstract}
Sound radiation from electric motor-driven vehicles is negligibly small compared to sound radiation from internal combustion engine automobiles. When running on a local road, an artificial sound is required as a warning signal for the safety of pedestrians. In this study, an engine sound was synthesized by combining artificial mechanical and combustion sounds. The mechanical sounds were made by summing harmonic components representing sounds from rotating engine cranks. The harmonic components, including not only magnitude but also phase due to frequency, were obtained by the numerical integration method. The combustion noise was simulated by random sounds with similar spectral characteristics to the measured value and its amplitude was synchronized by the rotating speed. Important parameters essential for the synthesized sound to be evaluated as radiation from actual engines were proposed. This approach enabled playing of sounds for arbitrary engines. The synthesized engine sounds were evaluated for recognizability of vehicle approach and sound impression through auditory experiments.
\end{abstract}

\section{Introduction}

With the increasing use of electric motor-driven vehicles due to their advantages such as environmental friendliness and fuel-efficient performance [1], it is necessary to generate artificial sounds to inform pedestrians and cyclists of the vehicle's approach. In addition, drivers prefer sounds similar to internal combustion engines for auditory satisfaction, and the sounds should represent the current status (acceleration or deceleration) of the vehicle, for example, start-up or rapid acceleration and deceleration. A simple method of generating artificial engine sounds is to play recorded combustion engine sounds according to engine rotating speeds. However, this method exhibits limited performance for reproducing the complex conditions of a vehicle and requires an impractical number of recordings for generating artificial sounds for various vehicle statuses from a single machine. An artificial engine sound generator is considered the most effective solution. This sound generator should be designed to make a positive impression on people to minimize the possibility of noise pollution.

Subjective evaluations of various engine sounds were performed in previous studies [2-5]. Amman and Das [6] proposed deterministic and stochastic components and used synchronous discrete Fourier transform and suboptimal multipulse excitation approaches to generate realistic engine sounds. Airplane engine sounds were generated by combining broadband and individual tonal contributions $[7,8]$ to determine the annoyance level and how to reduce it efficiently. Hastings [9] used deterministic and random variation in sound amplitude to regenerate diesel engine sounds. With amplitude variation following a rotating crank shaft, the random signals generated with impulse trains were used to generate artificial sounds for annoyance evaluation. Artificial engine sound generators mounted on low noise vehicles have used simple sounds for warning pedestrians outside the vehicle. The playing of sampled engine sounds for various rotating speeds was widely used in previous studies on artificial engine sound synthesis [10-18]. A system has been developed to warn pedestrians by using sine wave sweep signals [10-13], motor sounds [14], and future-oriented new sounds using instrument sounds [15]. The synthesizing method utilizing the premeasured actual engine sounds has the advantage of using less memory, but there is a limitation in creating a variety of sounds in relation to the vehicle speeds.

Active noise control and active sound design techniques have been used to reduce low-frequency engine noise and 
synthesize harmonics to enhance existing engine sound quality [16]. The artificial complex sounds were required to minimize noise according to the driving conditions of the vehicle $[17,18]$. Equalizers have been developed to allow setup of parameters adjusting the amplitude and range of the spectrum of basic sound building blocks.

In this study, an artificial engine sound generator was developed using a sample-based algorithm. With the systematic data processing, engine sounds that are similar to the actual engine sound are generated. Artificial engine sound synthesis method was implemented by analyzing the actual engine sound generation mechanism. The numerical integration method allows construction of an optimal data set generating the engine sound. Synthesized artificial engine sounds according to the vehicle engine speed were generated by applying a sample-based algorithm.

Many researches recorded and used the actual vehicle engine sound for sound synthesis. The artificial engine sound generator requires a CAN (controller area network) bus communication module and a sound module. This method is simple to use and implements actual engine sounds (or presynthesized beeps), but the types and scalability of sounds are limited and require a lot of memory. The auditory satisfaction of the user is also limited because it is difficult for the user to change the sound. To generate engine sounds, parameters related to engine characteristics such as number of cylinders, rotating speed, engine type, combustion pressure profile, timing, and amplitude modulation should be considered. For generation of engine sounds to be unique for each vehicle, important parameters that influence engine sound perception should be fully understood.

In this study, a mathematical formulation to generate artificial engine sounds to meet consumer preferences is proposed. With this approach, flexible generation of engine sounds without playing sampled sounds is possible. To analyze the characteristics of engine sounds, gasoline and diesel engine sounds were recorded. After spectrum analysis, the mechanical and combustion engine sounds were separated. The mechanical sounds were synthesized using a summation of tonal sounds. The combustion sounds were generated using spectrum amplitude-modulated random sounds to exhibit a specific frequency envelope. The artificial engine sound was synthesized by combining these mechanical and combustion engine sounds. For illustration, several different engine sounds were generated and used in the evaluation of perception. Recognizability of vehicle approaches and perceived quality of the artificial engine sounds were evaluated by comparison to actual recorded engine sounds. This also provided information on the sound generation mechanism for actual engines and its perceived characteristics. Engine sound characteristics must be understood for both design of quiet vehicle engines and artificial engine sound-producing devices.

\section{Measurements of Acoustic Characteristics of Engine Sounds}

Gasoline and diesel engine sounds were measured using the test engines in the laboratory $[19,20]$ for spectrum

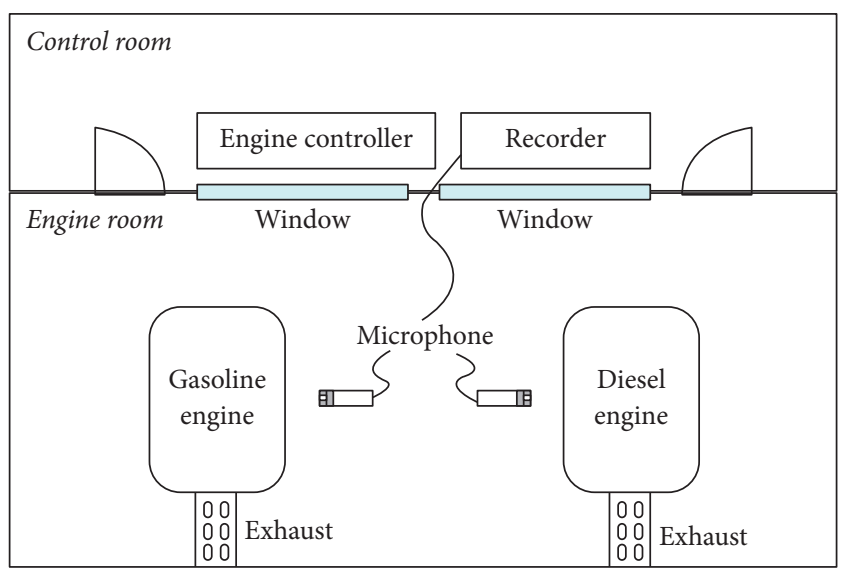

FIGURE 1: Overall schematic view of the laboratory chamber.

analysis. The measured engine noise was used to define the mechanical and combustion noise. Figure 1 shows the experimental setup to measure the engine sound. Figure 1 shows an overall schematic view of the laboratory chamber that has the controller adjusting operating conditions. The microphone used to measure sounds from each engine was located 1 meter from the engine. The engines used in the experiment were equipped with 4 cylinders. The engine room was surrounded by walls made of glass and porous panels. The sounds were measured for 10 seconds when the engine speed was $1000,1500,1800$, and $2100 \mathrm{rpm}$, with idle conditions of 850 and $820 \mathrm{rpm}$ for gasoline and diesel engines, respectively.

Figure 2 compares the sound of the gasoline engine to that of the diesel engine at various rotation speeds. The measured results were focused on the spectrum characteristics of the mechanical sound and the combustion sound. The highfrequency component of the diesel engine combustion noise was higher than that of the gasoline engine.

The combustion noise propagates into the air through the vibration of the various structures that make up the engine. The factors affecting the pressure profile include injection strategy, combustion chamber geometry, air-fuel mixture ratio, compression ratio, and amplitude changes due to explosion [20-24]. The resonance frequency of the crankcase and the cylinder block in the range of 200 to $1000 \mathrm{~Hz}$, the timing gear, the rocker cover in the range of 1000 to $5000 \mathrm{~Hz}$, and the cast aluminum cover and the thin cast iron in $5000 \mathrm{~Hz}$ were analyzed. The engine structures have different emission efficiencies. The frequency components were attenuated by more than $10 \mathrm{~dB}$ after $1 \mathrm{kHz}$ for the diesel engines [25]. The contribution of the noise generated in the wide band over $1 \mathrm{kHz}$ is relatively low compared to the mechanical sound of the tonal components. The sound level is reflected in frequencies and bands magnitude multiplied by artificial mechanical and combustion sounds. The lowfrequency region of the measured sound was masked by the mechanical sound. The mechanical and the combustion sounds were separated with respect to the frequency of $1 \mathrm{kHz}$. This distinction provided a simple but accurate algorithm for generating artificial engine sounds. 


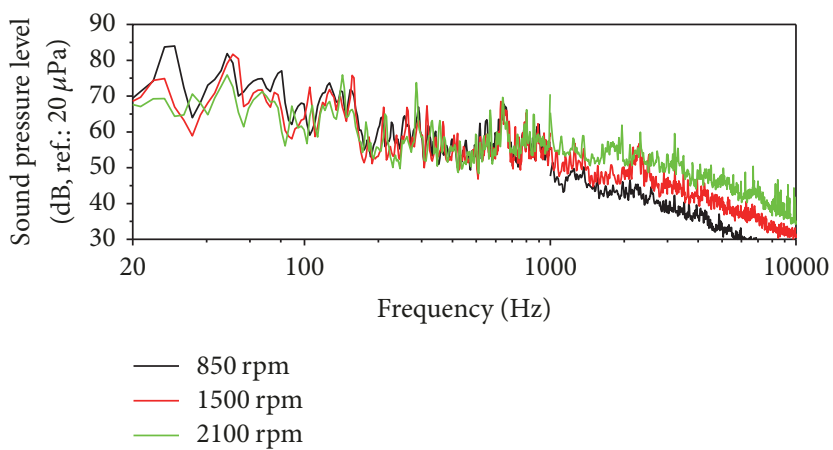

(a)

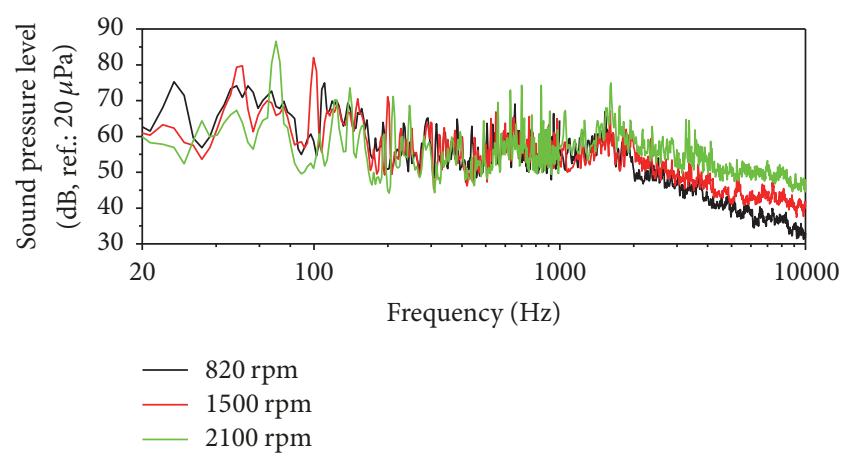

(b)

FIGURE 2: Spectral characteristics of (a) gasoline and (b) diesel engine sounds measured in the laboratory. The spectrum showed a decreasing level with increasing frequency, and the combustion noise at high frequencies over $1 \mathrm{kHz}$ was larger for the diesel engine.

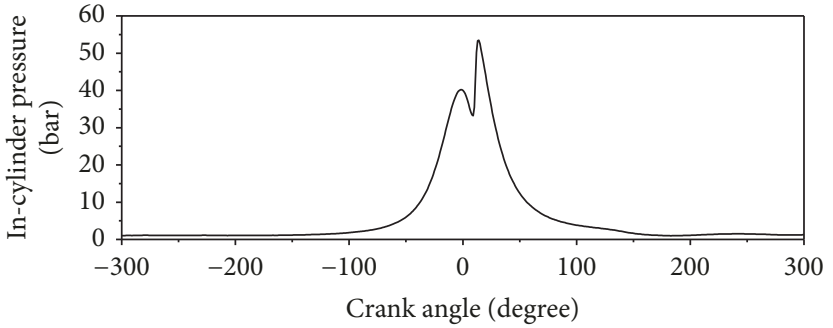

(a)

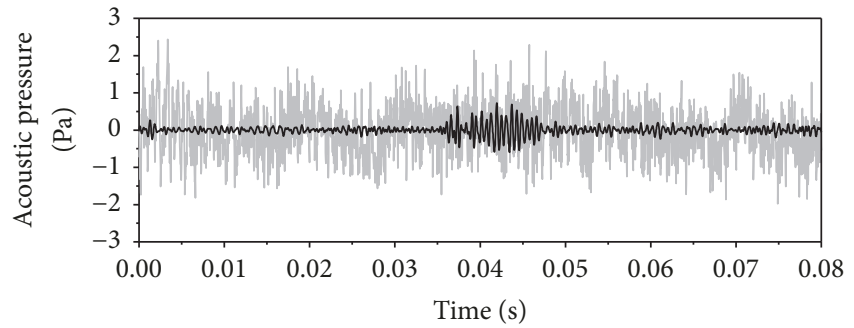

(b)

Figure 3: Comparison between (a) in-cylinder static pressure and (b) acoustic pressure for a single-cylinder diesel engine. For the acoustic pressure, the gray and black lines show measured and filtered (from 1.1 to $2.9 \mathrm{kHz}$ and 1.9 to $2.1 \mathrm{kHz}$ ) acoustic pressures to minimize influence from the dynamometer used in the experiments.

2.1. Spectral Characteristics of Engine Sounds. The frequency components of the measured engine sounds are shown in Figure 2. The measured sound was divided into mechanical and combustion sounds to produce artificial engine sound. The mechanical sound clearly shows the frequency shift in accordance with the engine speed in the low-frequency range. The combustion noise was defined for spectral components higher than $1 \mathrm{kHz}$, where the increase in the noise level of the broadband noise is noticeable depending on the engine speed. Although the combustion sound also affects the lowfrequency range according to the cylinder internal pressure conditions $[23,24]$, the variation of the combustion sound level by the mechanical sounds was negligibly small. At frequencies below $1000 \mathrm{~Hz}$, the engine sound level showed minimal dependence on the engine speed but showed a significant influence from the first engine order defined as

$$
f_{0}=N \cdot \frac{n}{2} \cdot 60
$$

where $N$ is the engine speed which is represented in revolutions per minute (rpm) and $n$ is the number of cylinders. The harmonic components at multiples of the first engine order had a significant influence at low-frequency bands, below $600 \mathrm{~Hz}$, and are known as mechanical sounds [3, $21,22,25,26]$. The combustion sounds measured for the diesel engine at frequencies between 1 and $10 \mathrm{kHz}$ were much higher compared to those of the gasoline engine. The high in-cylinder pressure of the diesel engine for autoignition caused this increased level of the combustion sound [26, 27]. The basic spectrum envelope of the frequency response between combustion and acoustic pressure remains the same for most diesel engines $[4,25]$. The combustion sound level is proportional to the engine speed in the fixed injection strategy and idle state.

2.2. Transient Variation in Engine Sounds. One important characteristic of diesel engine sounds is the temporal variation $[3,15]$. Direct injection diesel engines are often shortcircuited to the cylinder prior to the top dead center (TDC), often expressed as zero degrees of crank. Ignition occurs at 10 degrees prior to the combustion [28]. The first peak of the combustion pressure is due to the mechanical action of compressing the air in the second stroke. The second peak is caused by the sudden change in the sound pressure during the combustion process. For further investigation of combustion sound, a single-cylinder diesel engine [29, 30] was used for recording. To prevent reflection of engine sounds, an absorbing chamber was installed around the engine system. The engine sounds were recorded using a microphone which was located in front of the engine at a height of $1 \mathrm{~m}$. The incylinder pressure was measured at the same time.

Since the measured engine sound shown in Figure 3 included noise from various components of the test engine, the measured engine sound was bandpass-filtered from 1.1 
to $2.9 \mathrm{kHz}$ and from 1.9 to $2.1 \mathrm{kHz}$. The temporal variation in filtered sound due to the combustion cycle is clearly demonstrated in Figure 3. Comparing the temporal variation to the time history of the in-cylinder pressure shows that combustion sound is boosted periodically with the incylinder pressure change. The first maximum in the incylinder pressure was from the piston's mechanical movement during the compression stroke; the second maximum is from the combustion during the explosion stroke. Therefore, it is apparent that a combustion sound has a certain frequency envelope above $1 \mathrm{kHz}$ and it is amplitude-modulated in accordance with the mechanical cycling motion of the cylinder.

\section{Development of a Synthesis Method for Artificial Engine Sound}

Based on the measured spectral characteristics of engine sound, mechanical sound below $1 \mathrm{kHz}$ was especially dominant for the gasoline engine. The combustion sound above $1 \mathrm{kHz}$ had significant influence on the diesel engine sound. According to this measured variation, an artificial engine sound was synthesized by summing synthesized mechanical and combustion sounds.

3.1. Mechanical Sound Synthesis. Mechanical engine sound below $1 \mathrm{kHz}$ was synthesized by summing the harmonic components according to first engine order as

$$
p_{m}(t)=\sum_{k=1}^{K}\left(a_{k} \cos \left(\frac{2 \pi k f_{0} t}{N_{m}}\right)+b_{k} \sin \left(\frac{2 \pi k f_{0} t}{N_{m}}\right)\right),
$$

where $p_{m}$ is the mechanical sound and $N_{m}$ is the resolution for obtaining spectral components lower than the first engine order $\left(N_{m}=n^{2}\right)$. The magnitude of each frequency component, $a_{k}$, and phase, $\phi_{k}$ (the Fourier coefficients of the cosine and sine terms, $a_{k}$ and $b_{k}$ ), was obtained from spectrum analysis of the actual engine sounds measured for $10 \mathrm{~s}$. Because a typical spectrum analysis such as fast Fourier transform provides information only about the magnitude without phase, an integration method was applied to obtain both of them in this study as

$$
\begin{aligned}
& a_{k}=\frac{1}{M} \sum_{m=1}^{M}\left(\frac{1}{T} \int_{0}^{T} p(t+(m-1) T) \cos \frac{2 \pi k t}{T} d t\right) \\
& b_{k}=\frac{1}{M} \sum_{m=1}^{M}\left(\frac{1}{T} \int_{0}^{T} p(t+(m-1) T) \sin \frac{2 \pi k t}{T} d t\right),
\end{aligned}
$$

where $d t$ is the discrete-time interval of the recorded engine sound $p(t), T$ is the integration period considering resolution for obtaining spectral components, and $M$ is the number of samples of time averaging as recording time over $T$. Note that the summation of (3) means a time averaging. To solve the above integration numerically, Simpson's 1/3 rule was applied. Using the integration and time averaging, random noise components including the combustion noise become negligible. Therefore, only the mechanical sound components can be obtained. The magnitude of each frequency component $A_{k}$

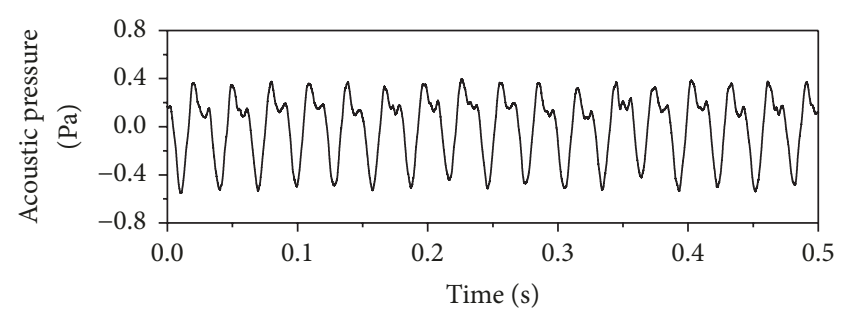

(a)

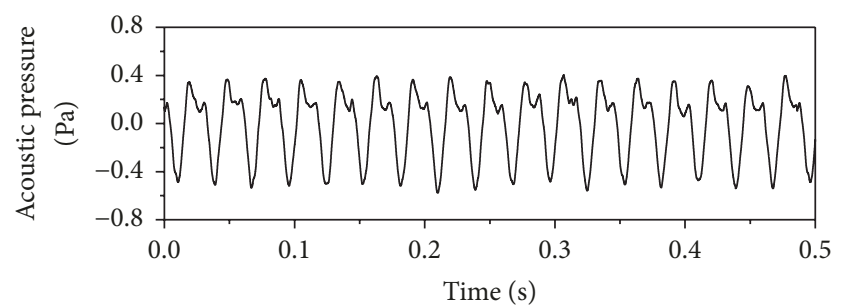

(b)

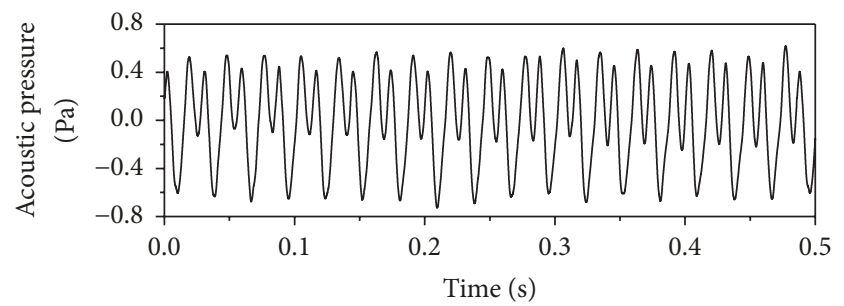

(c)

FIGURE 4: Comparison between (a) measured engine sound and (b) synthesized engine sound. The mechanical sound was varied by adjusting the amplitude (the amplitudes at frequencies $2 f 0$ and $10 f 0$ were amplified 2 and 10 times and are shown in (c)).

and phase $\phi_{k}$ was expressed for convenience of calculation of the mechanical sound synthesis.

$$
\begin{aligned}
A_{k} & =\sqrt{a_{k}^{2}+b_{k}^{2}} \\
\phi_{k} & =\tan ^{-1} \frac{b_{k}}{a_{k}} .
\end{aligned}
$$

Figure 4(a) shows the measured mechanical sounds and Figure 4(b) shows the synthesized engine sound under idle conditions. Note the low-frequency envelope of $8 \mathrm{~Hz}$ (repeating every $0.15 \mathrm{~s}$ ) in the signal. This low-frequency envelope originated from the cyclic motion of the engine piston and differences in the firing process between the cylinders and significantly influenced the development of realistic engine sounds. This low-frequency component is crucial for making specific engine sounds. In addition, by changing the frequency components and their magnitude and phase in (2), the synthesized engine sound changed as shown in Figure 4(c).

3.2. Combustion Sound Synthesis. Combustion sound has a specific frequency envelope above $1 \mathrm{kHz}$ and is amplitudemodulated with piston movements. Considering the fixed aspects of the changes in the amplitudes and the time 
TABLE 1: Stimuli used in the auditory experiments.

\begin{tabular}{|c|c|c|}
\hline Type & Number & Description \\
\hline \multirow{3}{*}{ Synthesized engine sound } & (a) & Mechanical sound of a gasoline engine \\
\hline & (b) & Mechanical sound of a diesel engine \\
\hline & (c) & Mechanical and combustion sound of a diesel engine \\
\hline \multirow{4}{*}{ Recorded real engine sound } & (d) & Gasoline engine, $2000 \mathrm{cc}$ displacement (reference stimulus) \\
\hline & (e) & Diesel engine, $2000 \mathrm{cc}$ displacement \\
\hline & (f) & Sports car engine, $6000 \mathrm{cc}$ displacement \\
\hline & (g) & Sports car engine, $4000 \mathrm{cc}$ displacement \\
\hline
\end{tabular}

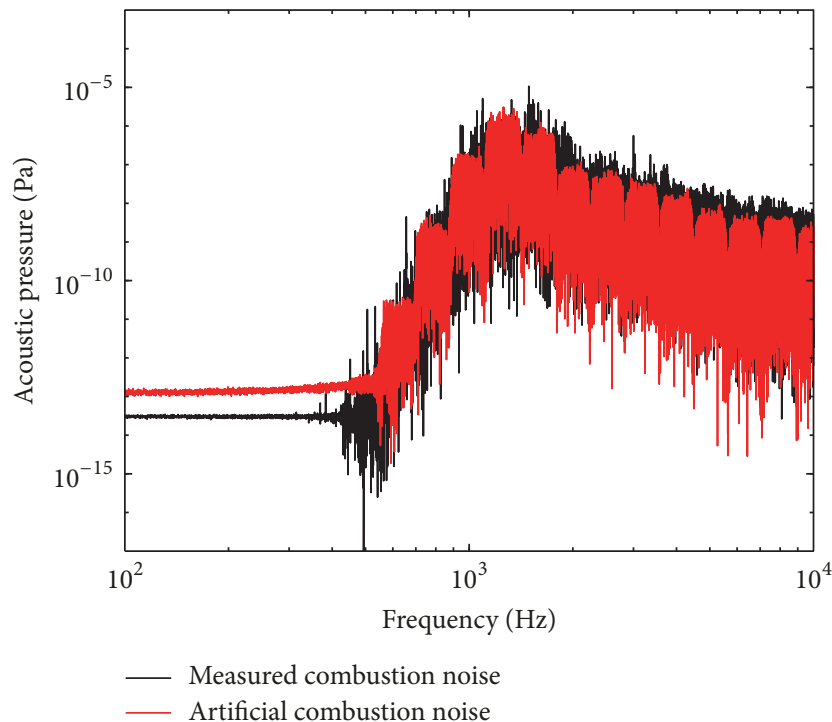

FIGURE 5: Typical combustion sound spectrum, which is composed of magnitude-adjusted noise bands from sampled white noise with 1/3-octave band.

characteristics of the mechanical sounds and the random signal characteristics of the broadband frequencies of the combustion noise, it is shown that they can produce sounds similar to those of real diesel engines [9]. The coefficients to adjust the total noise level and to change the fixed time characteristic of the mechanical sound as shown in (5) were used. It was possible to produce noise that is similar to the actual combustion noise. According to the spectrum characteristics of the combustion sound, the artificial spectrum, $p_{e}$, was generated using white noise sampled with $1 / 3$-octave bands and the magnitude of each band was adjusted for generating an arbitrary combustion engine as shown in Figure 5. After inverse Fourier transform, the combustion sound was made as

$$
p_{c}(t)=C \cdot M_{f} \cdot p_{e}(t) \cdot\left[p_{m}(t)+C_{r} \cdot M_{f}\right],
$$

where $p_{c}$ and $M_{f}$ are the combustion sound and the magnitude of the first engine order component, respectively. The magnitude coefficient, $C$, is a ratio of $M_{f}$ and was determined to be between 0.005 and 0.05 , based on measured typical diesel engine-driven vehicle noises at low and high rotation speeds. The broadband noise component considering reverberation effects by resonance in the combustion chamber

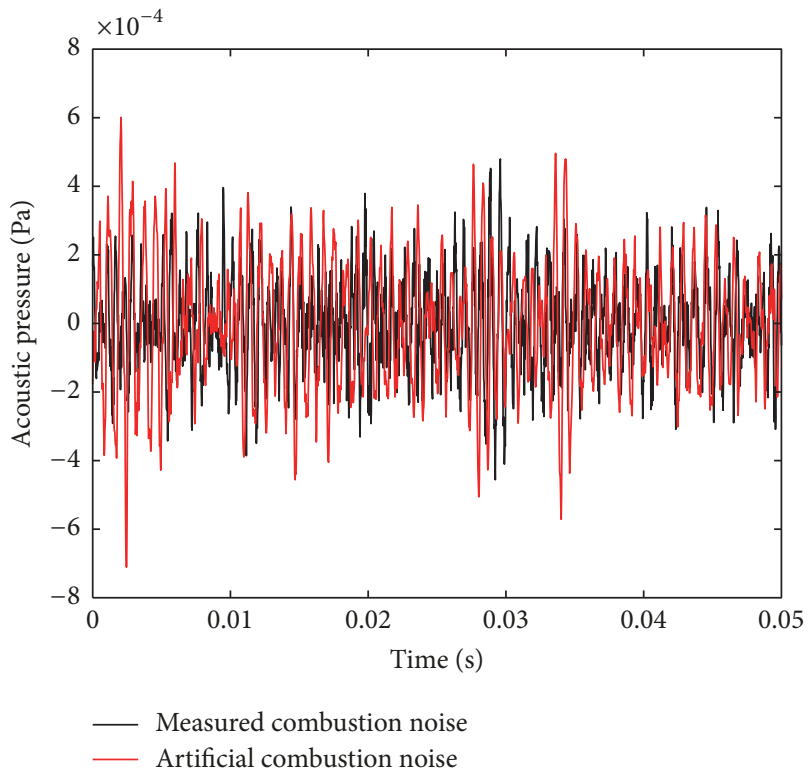

FIGURE 6: Acoustic pressure fluctuations of the measured and synthesized combustion sounds.

and repetitive explosive excitations was considered to be a constant $C_{r}$. The reverberation coefficient $C_{r}$ was determined to be between 2 and 4 at low and high rotation speeds. Consequently, the combustion sound was synchronized in magnitude with the mechanical sound. Figure 6 shows an example of synchronized engine sound in Figure 4(a) under constant rotation of the engine. Total engine sound was generated by summing the mechanical and combustion engine sounds.

\section{Validation of Synthesized Engine Sound through an Auditory Experiment}

To compare the performance of actual and artificial engine sounds, auditory experiments were performed using the magnitude estimation method [31]. Seven sound samples were used in the experiments. Figure 7 shows the acoustic pressure profile of the stimuli during idle condition for various recorded and synthesized engine sounds in Table 1. The engine rotating speed was increased gradually from $800 \mathrm{rpm}$ and reached a maximum rpm of $3000 \mathrm{rpm}$ and decreased to the idle condition again. The maximum sound 


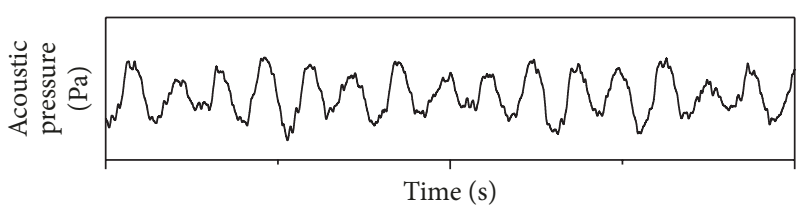

(a)

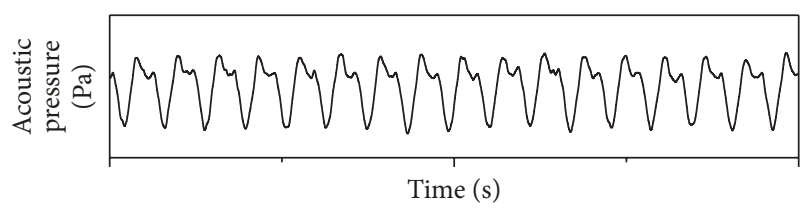

(b)

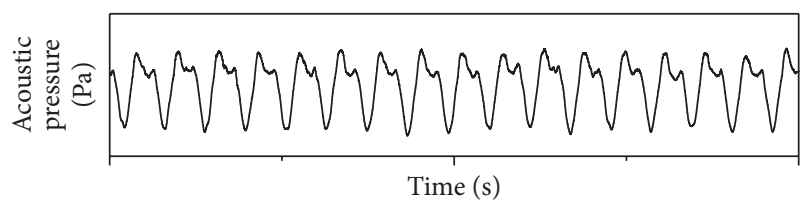

(c)

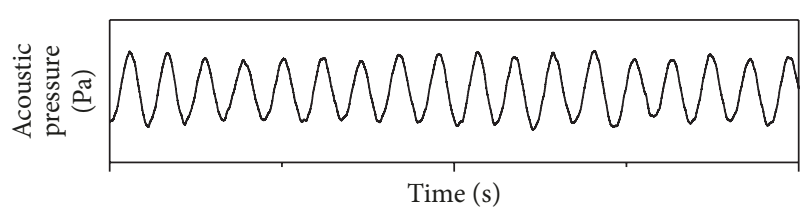

(d)

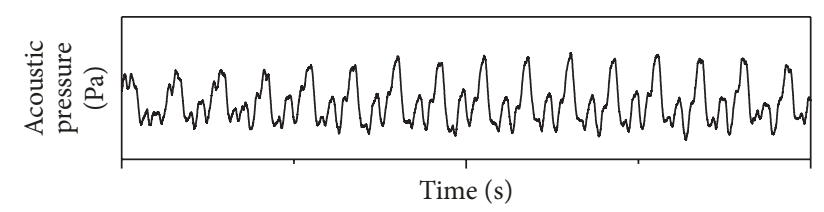

(e)

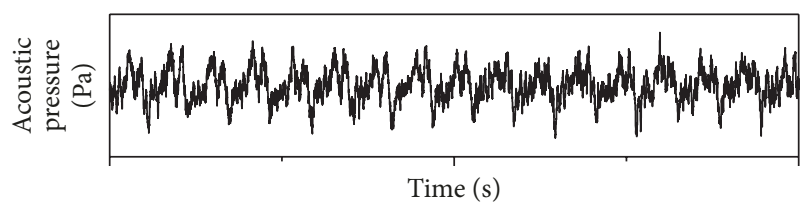

(f)

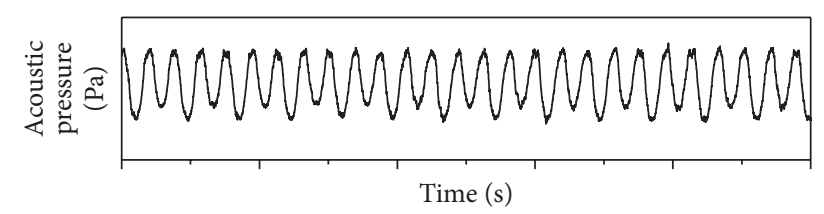

(g)

Figure 7: Acoustic pressure profiles of stimuli used in the auditory experiment. The sounds from (a) to (c) are the synthesized sounds and the sounds from (d) to (g) are the measured sounds. The $x$-axis of each layer indicates time in seconds of $0-0.5$, respectively.

level of each stimulus was adjusted to be $70 \mathrm{dBA}$. Figure 8 shows an example of acoustic pressure variation for the sound sample shown in Figure 7(a) during playback.

The stimuli were presented to 23 participants with normal hearing using loudspeakers in a soundproof room in which the sound level was lower than $38 \mathrm{dBA}$. Participants were

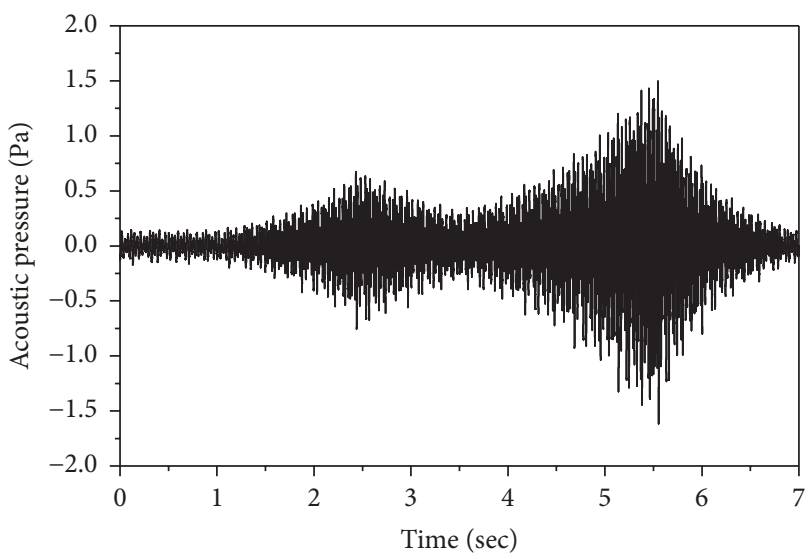

FIgURE 8: Acoustic pressure variation due to rpm change of stimuli used in the auditory experiment.
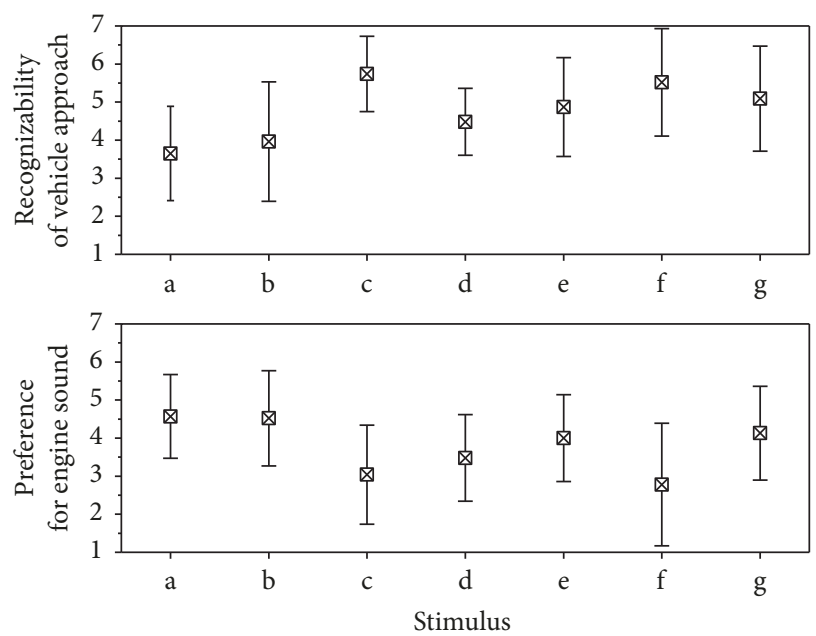

FIGURE 9: Results of the auditory experiments to evaluate the recognizability of vehicle approach and preference for engine sound.

asked to evaluate the recognizability of the vehicle approach and a preference for engine sounds when a stimulus was given. A typical gasoline engine sound (Figure 7(d)) was played three times as a reference stimulus that was set to four points for participants who were not used to evaluating using a seven-point scale method. Note that points 1 and 7 mean "extremely poor" and "extremely good," respectively.

The results of auditory experiments are summarized in Figure 9. Participants' consistency analysis was performed for subjective evaluation. Because stimulus (d), which was given as a reference, has an average of 4.48 and the standard deviation was small at 0.8 , the reliability of the result was verified. A synthesized diesel engine (stimulus c) shows the highest performance for achieving a recognizable vehicle approach. Compared to synthesized mechanical sounds only (stimuli a and b), the inclusion of the combustion sounds significantly increased the recognizability of engine sounds. The recorded sounds of sports cars (stimuli $f$ and g) showed high performance, but not higher than that of stimulus $\mathrm{c}$. 
Synthesized gasoline engine sounds (stimuli a and b) exhibited better performance than that of the diesel engine (stimulus c). This suggested that a more annoying sound made pedestrians clearly recognize a vehicle approach. The sports car engine sound (stimulus g) has better engine sound preference than the other sounds (stimuli c, d, e, and f). The strongly fluctuating sounds of the sports vehicles were one reason for this large variation.

\section{Conclusions}

In this study, the transient and spectrum variation of recorded sounds from the test engines in a lab was analyzed to investigate the effects of piston cyclic motion on the radiation of mechanical and combustion engine sounds and their correlation to frequency components. Artificial engine mechanical sound was synthesized using summation of sinusoidal waves representing mechanical sounds. Due to small differences in the frequency of sounds radiating from each cylinder, a modulated mechanical sound was generated. For representing mechanical sounds with harmonic sums without influence of the combustion noise, the Fourier series was used with the fundamental frequency smaller than the first engine order. After considering these frequency components less than the rotating speeds, the synthesized mechanical sounds exhibited similar characteristics to actual gasoline engine sounds. The combustion sound was synthesized using a spectrumenveloped random signal. The engine sound was generated by combining these mechanical and combustion sounds. This approach enables generation of arbitrary engine sounds to customer preference for their own vehicles. From the results of the auditory experiments, recognizability of vehicle approach and preference for engine sound were compared to actual engine sounds. The synthesized sounds, especially for the diesel engine, showed excellent performance for informing participants of vehicle operation. The proposed algorithm utilizes variations in frequency components with rotating speeds and allows the use of various sound sources from musical instruments. Consequently, pleasant sounds may inform pedestrians of a vehicle approach.

\section{Data Availability}

The data used to support the findings of this study are available from the corresponding author upon request.

\section{Conflicts of Interest}

The authors declare no conflicts of interest.

\section{Acknowledgments}

This work was supported by the Research Fund of Hanyang University (HY-2017) and LG Electronics Company.

\section{References}

[1] M. S. Wogalter, R. N. Ornan, R. W. Lim, and M. R. Chipley, "On the Risk of Quiet Vehicles to Pedestrians and Drivers,"
Proceedings of the Human Factors and Ergonomics Society Annual Meeting, vol. 45, no. 23, pp. 1685-1688, 2001.

[2] H. Aoki, M. Ishihama, and A. Kinoshita, "Effects of power plant vibration on sound quality in the passenger compartment during acceleration," SAE Technical Papers, Article ID 870955, 1987.

[3] M. F. Russell, S. A. Worley, and C. D. Young, "Towards an objective estimate of the subjective reaction to diesel engine noise," SAE Technical Paper, 1987.

[4] K. Schmillen and J. Wolschendorf, "Cycle-to-cycle variations of combustion noise in diesel," SAE Technical Papers, Article ID 890129, 1989.

[5] T. Hashimoto, S. Hatano, and H. S. Isuzu, "Improvement of sound quality of exterior idling noise of small diesel truck," $S A E$ Technical Papers, Article ID 951289, 1995.

[6] S. A. Amman and M. Das, "An efficient technique for modeling and synthesis of automotive engine sounds," IEEE Transactions on Industrial Electronics, vol. 48, no. 1, pp. 225-234, 2001.

[7] D. Berckmans, K. Janssens, H. Van der Auweraer, P. Sas, and W. Desmet, "Model-based synthesis of aircraft noise to quantify human perception of sound quality and annoyance," Journal of Sound and Vibration, vol. 311, no. 3-5, pp. 1175-1195, 2008.

[8] K. Janssens, A. Vecchio, and H. Van der Auweraer, "Synthesis and sound quality evaluation of exterior and interior aircraft noise," Aerospace Science and Technology, vol. 12, no. 1, pp. 114$124,2008$.

[9] A. L. Hastings, Sound Quality of Diesel Engines, Purdue University, USA, 2004.

[10] Hyundai, "Virtual Engine Sound System (VESS)," http://worldwide.hyundai.com, 2015.

[11] SoundRacer, "Electric Vehicle Electronic Engine Sound System (EVEESS)," http://eveess.com, 2015.

[12] Fisker Automotive, "Fisker Karma," http://thenewfisker.com, 2015.

[13] H. Konet, M. Sato, T. Schiller, A. Christensen, T. Tabata, and T. Kanuma, "Development of Approaching Vehicle Sound for Pedestrians (VSP) for Quiet Electric Vehicles," SAE International Journal of Engines, vol. 4, no. 1, pp. 1217-1224, 2011.

[14] Toyota, "Approaching Vehicle Audible System," 2015, http:// www.toyota-global.com.

[15] Audi. E sound, http://www.audi.com/en.html, 2015.

[16] Harman. HALOsonic., http://www.halosonic.co.uk/, 2015.

[17] T. Kuppers, "Results of a structured development process for electric vehicle target sounds," Aachen Acoustic Colloquium 2012, pp. 63-71, 2012.

[18] O. Engler, M. Hofmann, R. Mikus, and T. Hirrle, "MercedesBenz SLS AMG Coupé Electric Drive NVH development and sound design of an electric sports car," Internationales Stuttgarter Symposium, pp. 1295-1309, 2015.

[19] S. H. Yoon and C. S. Lee, "Lean combustion and emission characteristics of bioethanol and its blends in a spark ignition (SI) engine," Energy \& Fuels, vol. 25, pp. 3484-3492, 2011.

[20] K. Jeong, D. Lee, S. Park, and C. S. Lee, "Effect of two-stage fuel injection parameters on NOx Reduction characteristics in a DI diesel engine," Energies, vol. 4, no. 11, pp. 2049-2060, 2011.

[21] D. E. Baxa, Noise control in internal combustion engines, John Wiley and Sons, New York, USA, 1982.

[22] Y. Yawata and M. J. Crocker, "Identification of internal noise sources in diesel engines," SAE Technical Paper, Article ID 831330, 1985. 
[23] F. Payri, A. Broatch, B. Tormos, and V. Marant, "New methodology for in-cylinder pressure analysis in direct injection diesel engines - Application to combustion noise," Measurement Science and Technology, vol. 16, no. 2, pp. 540-547, 2005.

[24] A. J. Torregrosa, A. Broatch, J. Martín, and L. Monelletta, "Combustion noise level assessment in direct injection Diesel engines by means of in-cylinder pressure components," Measurement Science and Technology, vol. 18, no. 7, article no. 045, pp. 21312142, 2007.

[25] M. F. Russell and R. Haworth, "Combustion noise from high speed direct injection diesel engines," SAE Technical Papers, Article ID 850973, 1985.

[26] H. Kanda, M. Okubo, and T. Yonezawa, "Analysis of noise sources and their transfer paths in diesel engines," SAE Technical Papers, Article ID 900014, 1990.

[27] C. V. Beidl and A. Rust, "Meeting future demands for quieter commercial powertrain systems," SAE Technical Papers, Article ID 972042, 1997.

[28] J. B. Heywood, Internal combustion engine fundamentals, vol. 930, Mcgraw-hill, New York, USA, 1988.

[29] B. M. Spessert, "Noise reduction potential of single cylinder DI diesel engines," SAE Technical Papers, 2003.

[30] G. Chiatti and O. Chiavola, "Combustion Induced Noise in Single Cylinder Diesel Engines," SAE Technical Papers, 2004.

[31] S. S. Stevens, "Psychophysical Law: in Psychophysics," in Introduction to its perceptual, neural, and social prospects, Wiley, New York, USA, 1975. 


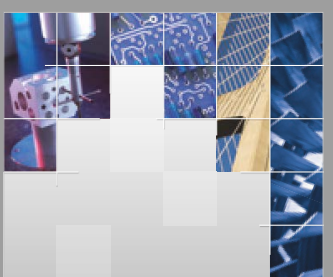

\section{Enfincering}
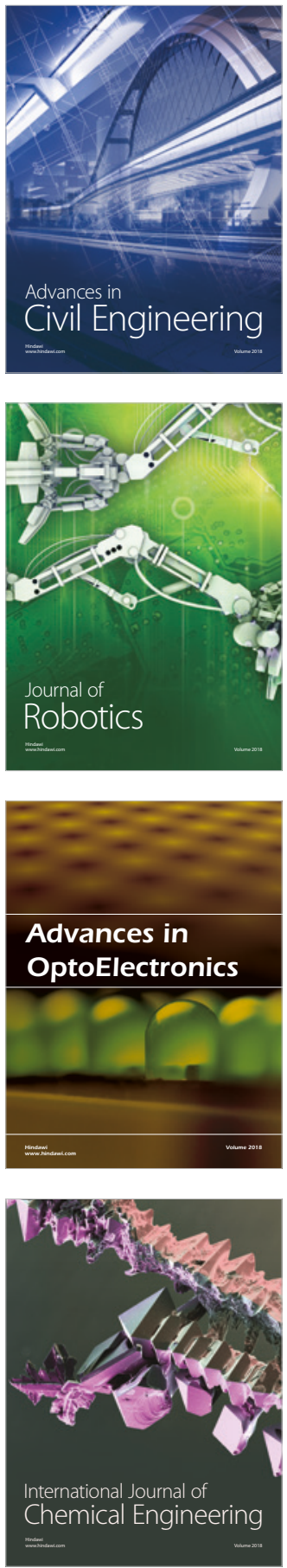

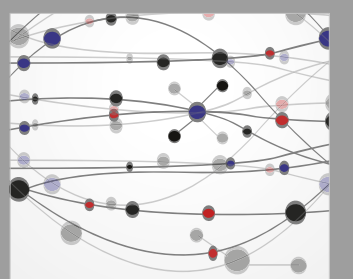

\section{Rotating \\ Machinery}

The Scientific World Journal

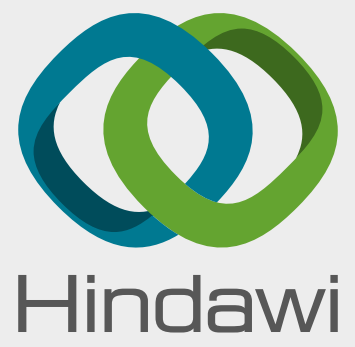

Submit your manuscripts at

www.hindawi.com
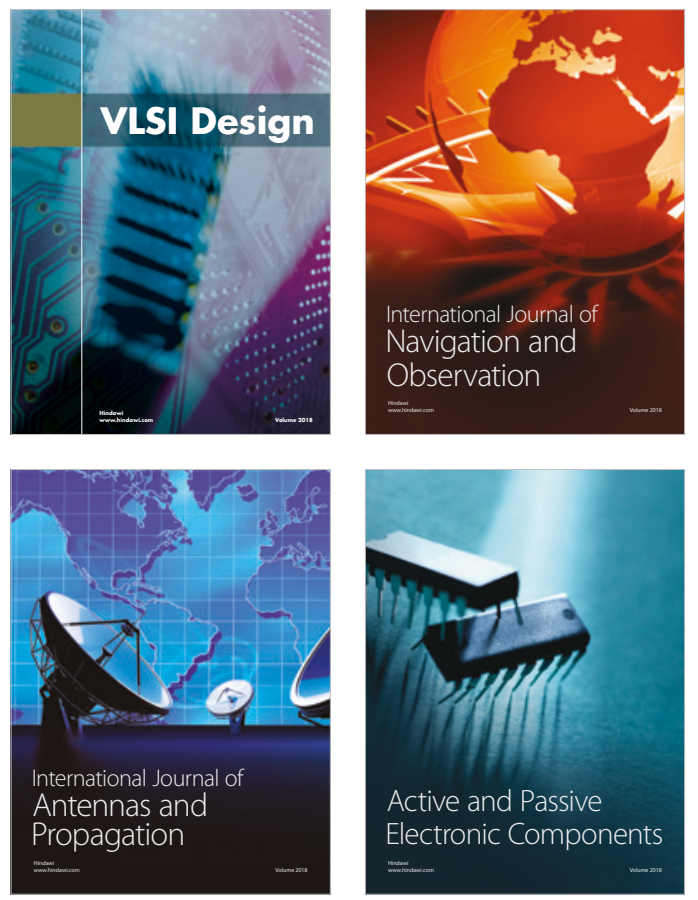
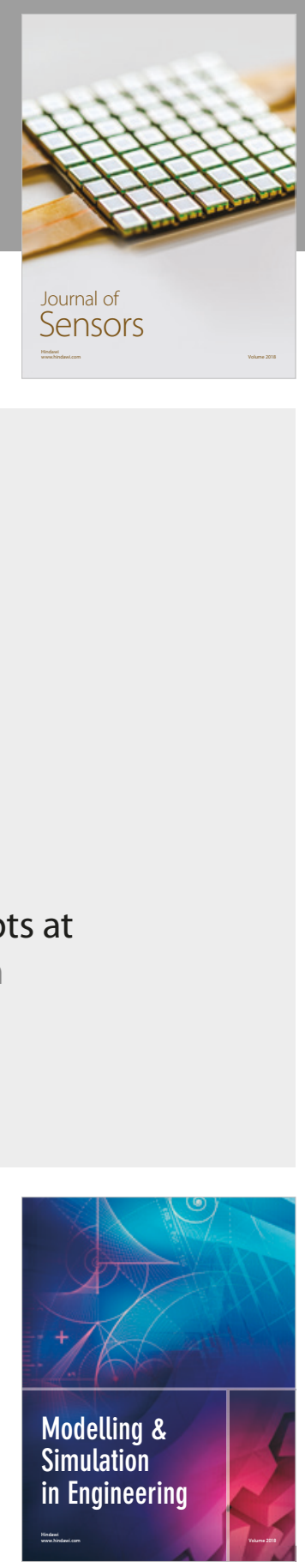

\section{Advances \\ Multimedia}
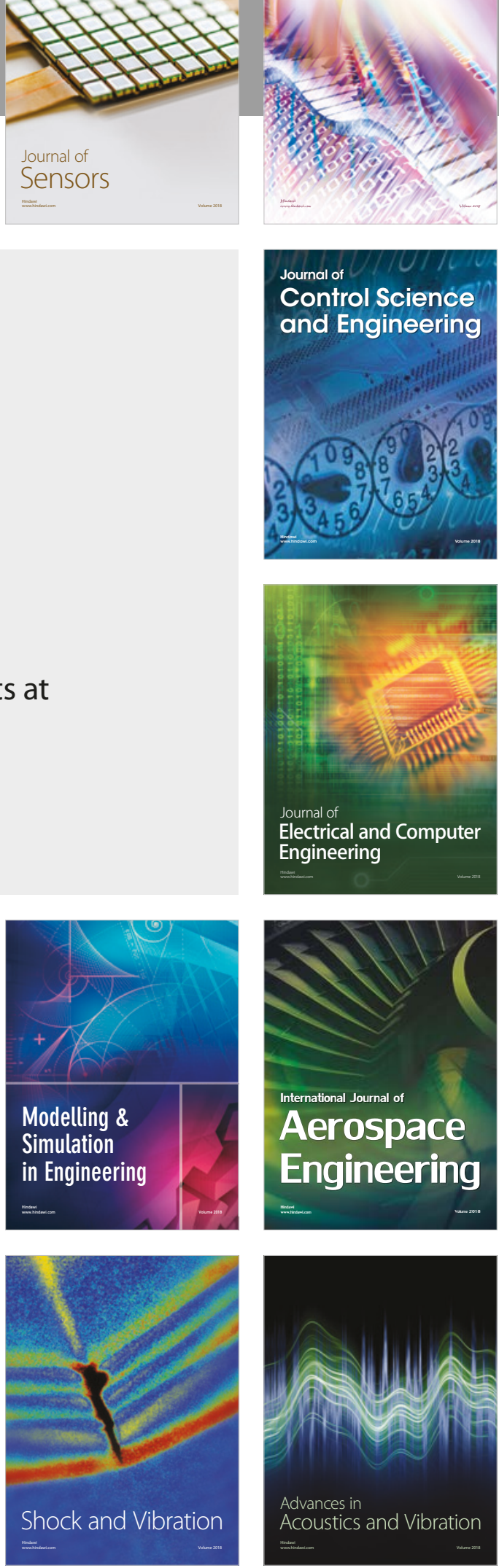